\title{
Adiabatic Differential Scanning Calorimetric Study of Divalent Cation Induced DNA - DPPC Liposome Formulation Compacted for Gene Delivery
}

\author{
Erhan Süleymanoglu* \\ Department of Physical Chemistry of Drugs; Faculty of Pharmacy; Biophysics Section; J. A. Comenius University; \\ Odbojarov 10; 83232 Bratislava; erhan@post.cz; and The Slovak Academy of Sciences; Institute of Experimental \\ Physics; Department of Biophysics; Kořice - The Slovak Republic
}

\begin{abstract}
Complexes between nucleic acids and phospholipid vesicles have been developed as stable non-viral gene delivery vehicles. Currently employed approach uses positively charged lipid species and a helper zwitterionic lipid, the latter being applied for the stabilization of the whole complex. However, besides problematic steps during their preparation, cationic lipids are toxic for cells. The present work describes some energetic issues pertinent to preparation and use of neutral lipid-DNA self-assemblies, thus avoiding toxicity of lipoplexes. Differential scanning calorimetry data showed stabilization of polynucleotide helix upon its interaction with liposomes in the presence of divalent metal cations. It is thus possible to suggest this self-assembly as an improved formulation for use in gene delivery.
\end{abstract}

Key words: Nucleic acid-phospholipid interactions, divalent cation-induced complex formation, phase transitions, microcalorimetry

\section{INTRODUCTION}

Nucleic acid-membrane associations comprise the least functionally studied macromolecular assembly, yet attract the attention of researchers due to their potential in the field of gene therapy (Leckband and Israelashvili, 2001). The design of novel nucleic acid delivery formulations proceeds mainly as searches of alternatives to highly efficient but risky viral based vehicles (Miller, 2003; Liu and Huang, 2002). The main objective is to achieve compaction of genetic material within highly restricted compartments, while decreasing its cytotoxicity. In the light of well-established potential of liposomes as gene carriers
(Templeton, 2001), the current work concerns mainly the stability and physical properties of DNA within the lipid surrounding. Such particles, referred to as lipoplexes are composed of positively charged lipid species and a helper neutral lipid, used for the stabilization of the liposome complex. Despite the considerable efforts that have been made to characterize the structure of these complexes, the origin of molecular forces responsible for self-assembly formation, determination of their charge, colloidal properties, stability against dissociations, cytotoxicity issues, and unravelling characteristics related to efficient intracellular delivery and gene expression remain unclear. A possible alternative to the toxic cationic lipids is the employment of

*Author for correspondence 
zwitterionic lipid species, which are much safer for target cells (Kharakoz et al., 1999). Neutral liposome-DNA self-organization is mediated by various inorganic cations, acting as condensing agents. In the light of recent strong evidence that divalent cations enhance the efficacy of plasmid DNA-cationic lipid formulations (Lam and Cullis, 2000), it is of particular interest to study the effect of different divalent cations on the transfection potency of lipid-DNA complexes. In this context, a preliminary results of promissing ternary DNADPPC- $\mathrm{Mg}^{2+}$ complex preparation and its thermodynamic properties are presented herein.

\section{MATERIALS AND METHODS}

Synthetic dipalmitoylphosphatidylcholine (DPPC) and calf thymus DNA were a kind gift of Prof. P. Bálgavy (J. A. Comenius University - Bratislava, Slovakia). EDTA was purchased from Sigma Chemical Co., St. Louis, MO, USA. $\mathrm{MgCl}_{2} \cdot 6 \mathrm{H}_{2} \mathrm{O}$, $\mathrm{NaHPO}_{4}$ and $\mathrm{NaCl}$ were obtained from Merck, Darmstadt, Germany. The presented nucleic acid concentrations and the molar ratios are based on the average nucleotide molecular weight of 308 calculated from the known DNA composition employed (Uhrikova et al., 1998).

\section{Preparation of vesicles}

$1.2 \mathrm{mM}$ lipid in standard SSC buffer $\left(1.5 \times 10^{-4}\right.$ $\mathrm{mol} / \mathrm{l} \mathrm{Na}$-citrate, $1.5 \times 10^{-3} \mathrm{~mol} / \mathrm{l} \mathrm{NaCl}, \mathrm{pH}=7.2$ ) was used in all the experiments and was stored at $4^{\circ} \mathrm{C}$. The formation of a thin layer of lipids in a $15 \mathrm{ml}$ round-bottomed flask was achieved by a handshaking and hydration in SSC buffer at around $70^{\circ} \mathrm{C}$. Vortexing of the lipid with the desired aqueous solution above the gel-to-liquid crystalline phase transition of the lipid $\left(\mathrm{T}_{\mathrm{m}}\right)$ for around $30 \mathrm{~min}$ resulted in multilamellar vesicles. The DNA concentration used troughout all the experiments was $1.8 \mathrm{mM}$ based on the above mentioned assumption. Unilamellar vesicles were obtained by extrusion of multilamellar vesicle suspension through two stacked polycarbonate filters (Nucleopore, Inc.) of $100 \mathrm{~nm}$ pore size at around $60^{\circ} \mathrm{C}$. Repeated extrusion $(10$ times $)$ through the extruder (Lipex Biomembranes, Inc., Vancouver, B. C., Canada) creates homogeneous vesicle suspension. This allows the preparation of vesicles with a mean diameter of $90 \mathrm{~nm}$ and a trap volume in the range of $1.5-2.0 \mathrm{l} / \mathrm{mole}$.

\section{Preparation of liposome-nucleic acid mixtures} DPPC-DNA formulations were obtained by mixing appropriate volumes of unilamellar vesicles dispersion, calf thymus DNA solution and $\mathrm{MgCl}_{2}$ solution in SSC buffer to obtain the desired molar ratios.

\section{Differential Scanning Calorimetry}

Differential scanning microcalorimetric measurements were performed employing Privalov type DASM-4 adiabatic differential scanning microcalorimeter (Russian Academy of Sciences-Puschino, Moscow Region), with a scan rate of $0.5 \mathrm{~K} \cdot \mathrm{min}^{-1}$. Instrumental base line calibration mark was obtained by scanning at 50 $\mu \mathrm{W}, \Delta \mathrm{T}=4$, as described (Ivanov, 1988).

\section{RESULTS AND DISCUSSION}

Although double-stranded DNA (dsDNA) has been shown to bind to zwitterionic lipids (Malghani and Yang, 1998), its thermodynamic stability features remain to be elucidated. Only results obtained with unilamellar DPPC vesicles have been presented, in the light of recent evidence for their better performance in gene delivery studies with respect to internalization mechanisms (Templeton, 2001). The interaction of calf thymus DNA with phosphatidylcholine liposomes in the presence of $\mathrm{Mg}^{2+}$ ions was studied using the adiabatic differential scanning microcalorimetry. Fig 1 depicts representative thermograms of DPPC liposomes and their complexes with DNA and $\mathrm{Mg}^{2+}$. The first curve on the top is calibration mark and shows a typical DPPC multilayer phase transitions, with pretransition $36^{\circ} \mathrm{C}$ with a $\Delta \mathrm{H}_{\mathrm{cal}}=3.9 \mathrm{~kJ} / \mathrm{mol}$ and the gel - liquid crystal, or main phase transition $\left(\mathrm{T}_{\mathrm{m}}\right)$ at $41.9^{\circ} \mathrm{C}$. The subsequent marked curves to the bottom represent the change of phase transitions upon interactions with various quantities of DNA and $\mathrm{Mg}^{2+}$. DPPC unilamellar vesicles' thermogram peak appears broader with a decreased maximum. The pre-transition peak disappears. The curve denoted for nucleic acid - phosphatidylcholine mixture (DPPC - DNA) indicated that phase separation occurred between unbound lipids and their complexes with nucleic acid, the lipid-DNA phase having its peak further at around $51.3^{\circ} \mathrm{C}$ when mixed in equimolar amounts (1:1). In this type of complex formation, the measured value of 
$\mathrm{T}_{\mathrm{m}}=41.9$ and $\Delta \mathrm{H}_{\mathrm{cal}}=31.9 \mathrm{~kJ} / \mathrm{mol}$ were determined. The interaction with liposomes resulted in the significant decrease of excess apparent specific heat capacity. The next three curves to the bottom marked as DPPC - DNA - $\mathrm{Mg}^{2+}$ show the phase behaviour of ternary mixtures of DPPC:DNA: $\mathrm{Mg}^{2+}$ in 1:1:1, 1:3:1 and 1:5:1 ratios with increased DNA amount, respectively. The equimolar peak possessed narrower signal, compared to DPPC vesicles' peak, with further DNA phase separation. The $\mathrm{T}_{\mathrm{m}}$ value remained, however $\Delta \mathrm{H}_{\text {cal }}$ diminished to $9.7 \mathrm{~kJ} / \mathrm{mol}$.

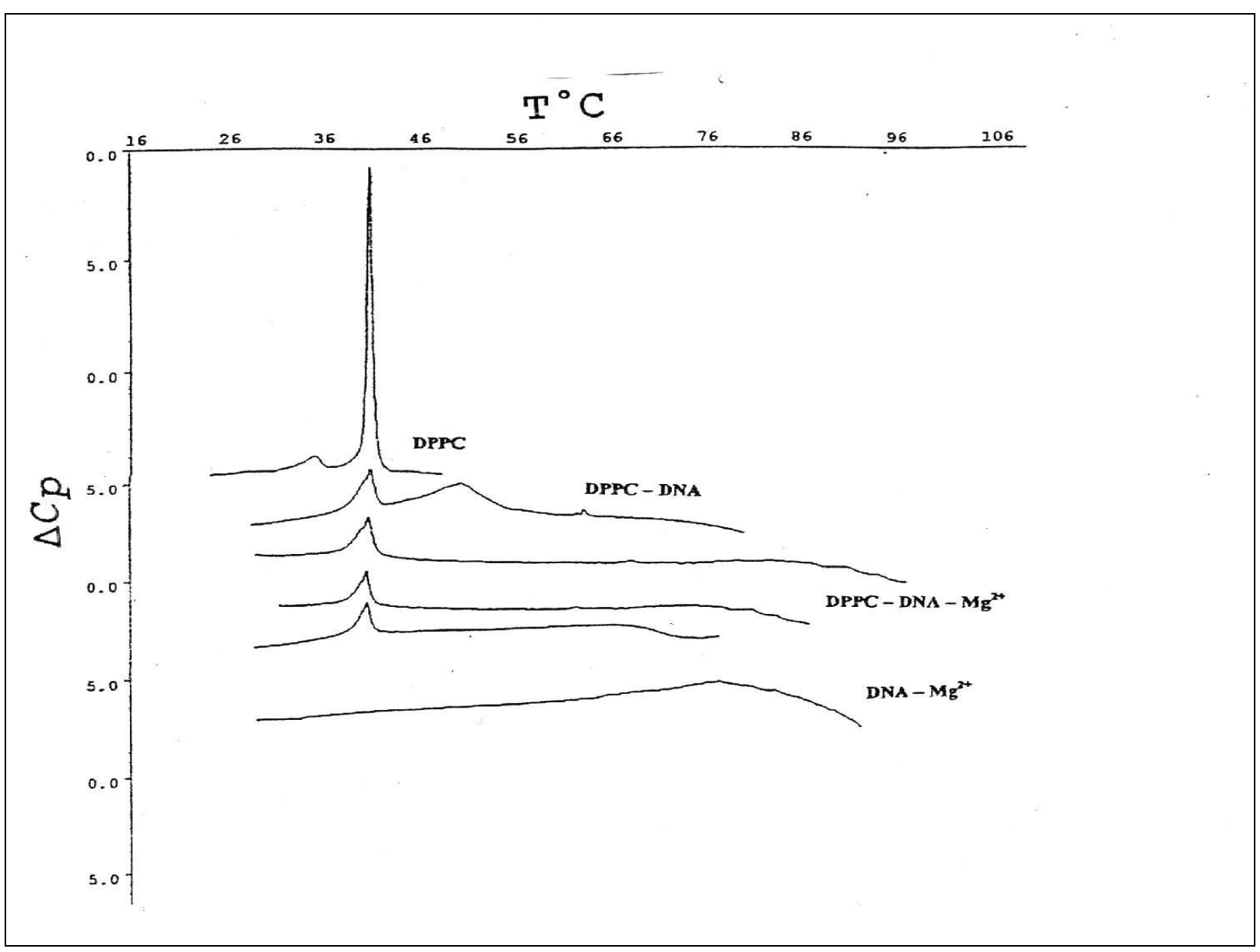

Figure 1 - DSC heating scans of the main phase transition of DPPC multilayers and unilamellar vesicles obtained from them, upon their associations with various amounts of calf thymus DNA and $0.5 \mathrm{mM} \mathrm{Mg}^{2+}$. Each complex is denoted in the abbreviated form. Data is presented as excess apparent heat capacity $(\triangle C p)$ vs. temperature $\left(\mathrm{T}^{\circ} \mathrm{C}\right)$ curves. Details of sample preparation and measurements are outlined in Materials and Methods.

The specific heat capacity remained upon complexation with divalent cation. The main phase transitions shifted somehow to $41.7^{\circ} \mathrm{C}$. Interestingly the DNA phase peak moved further to $89^{\circ} \mathrm{C}$. At the $1: 1: 1$ molar ratio of the triple complexation, the self - assemblies displayed two peaks. The first one was at main phase transition temperature corresponding to the melting of lipid dispersion. The second one was at $86^{\circ} \mathrm{C}$ and corresponded for the DPPC-DNA self-assembly. The latter peak was attributed to the stabilization of the DNA secondary structure by a tight packing of DNA molecules with several unilamellar vesicles, bridged by $\mathrm{Mg}^{2+}$-ions. This was a particular case of liposome surface induced nucleic acid condensation of the "spaghetti and meatballs" structure (Templeton, 2001). The effect was driven by surface cationization of vesicles, 
sensed by a conformational change in the choline group of DPPC. It tilted towards the bilayer surface plane since its positively charged quaternary nitrogen was attracted by the opposite charge of the nucleic acid polyanion. The main phase peak sharpened upon increasing the DNA amount twice, as shown in the next curve beneath. Interestingly, the lipid-DNA phase peak shifted to lower values of $71^{\circ} \mathrm{C}$. This trend was maintained upon increasing the DNA amount more (ternary molar ration of 1:5:1). The triple complex of DNA-metal ion-phosphatidylcholine vesicle remained stable at different incubation times, which was in agreement with small- and wideangle X-ray scattering measurements (Uhrikova et al., 1998). Apparently, $\mathrm{Mg}^{2+}$ decreased the DNA effective radii and created groove narrowing by ligand binding to six or eight water molecules, or alternatively to nucleic acid phosphate in the minor groove in a fully hydrated state (Hud and Polak, 2001). The last curve denoted as DNA $\mathrm{Mg}^{2+}$ represented equimolar mixture of DNA and $\mathrm{Mg}^{2+}$, which brought about a major signal at around $90^{\circ} \mathrm{C}$. The $\mathrm{Mg}^{2+}$ ions at the equimolar ratio of $\mathrm{Mg}^{2+}$ :DNA increased the $\mathrm{T}_{\mathrm{m}}$ value by $33.7^{\circ} \mathrm{C}$, reaching a maximum at $85^{\circ} \mathrm{C}$ due to $\mathrm{Mg}^{2+}$-induced phase separation with an increased gel - liquid crystal phase transition temperature, which indicated the divalent cation triggered high temperature DNA stabilization. Unilamellar vesicles treated with the same concentration of $\mathrm{Mg}^{2+}$ did not produce such a shift, which was normally detected spectroscopically. Obviously, here divalent metal cation did not contribute essentially in stabilizing the zwitterionic lipid structure. Therefore, DNA contributed to stabilization of ternary complex towards higher temperatures. Apparently, $\mathrm{Mg}^{2+}$ - DNA created polymorphic phase transitions in phosphatidylcholine moiety.

It is well-established that such a positively charged particle delivers DNA into cultured cells by electrostatic mechanisms of binding to their negatively charged membranes. Liposomes enter cells by various routes, such as through endocytic pathway and direct membrane fusion. Gene delivery designs involving receptor mediated transfer face problems, since endosomes fuse rapidly with lysosomes, thus degrading the nucleic acids. The ternary complex between nucleic acid, divalent inorganic cation and extruded liposomes formulated from zwitterionic lipids, described in this work could deliver genes into cells via direct fusion with the cell membrane. This model is in accordance with recent proposal (Templeton, 2001). The major advantage of such non-viral nanocondensate formulations is their ability to act across tight barriers in vivo.

\section{CONCLUSIONS}

Although superior in terms of gene delivery, viral systems lack safety. Results of this work showed that employing DNA-inorganic metal cationneutral liposome ternary complex was a promissing formulation in terms of increasing thermodynamic stability features, which were crucial for genosome stability in gene delivery trials.

\section{AKNOWLEDGMENTS}

My gratitudes go to Prof. P. Bálgavy (J. A. Comenius University-Bratislava) and Dr. J. Bagelova (Institute of Experimental Physics, The Slovak Academy of Sciences-Košice) for the hospitality and close supervision during my visit to Slovakia.

\section{REFERENCES}

Hud, N. V. and Polak, M. (2001), DNA - cation interactions: the major and minor grooves are flexible ionophores. Curr. Opin. Struct. Biol., 11, 293-301.

Ivanov, I. I. (1988), Chapter V: Calorimetric Methods of Studying Biopolymers and Membrane Systems. In: Rubin, A. B. (Ed.). Modern Methods of Biophysical Investigations - a Practicum of Biophysics. Moscow : Vishaya Shkola. pp. 203-216. [In Russian].

Leckband, D. and Israelachvili, J. (2001), Intermolecular forces in biology, Q. Rev. Biophys, 34, 105-267.

Kharakoz D. P.; Khusainova R. S.; Gorelov A. V. and Dawson K. A. (1999), Stoichiometry of dipalmytoilphosphatidylcholine - DNA interaction in the presence of $\mathrm{Ca}^{2+}$ : a temperature - scanning ultrasonic study. FEBS Lett, 446, 27-29.

Lam, A. M. I. and Cullis, P. R. (2000), Calcium enhances the transfection potency of plasmid DNAcationic liposome complexes, Biochim. Biophys. Acta, 1463, 279-290.

Liu, F. and Huang, L. (2002), Development of non-viral vectors for systemic gene delivery, J. Contr. Release, 78, 259-266. 
Malghani, M. S. and Yang, J. (1998), Stable binding of DNA to zwitterionic lipid bilayers in aqeous solutions, J. Phys. Chem B., 102, 8930 - 8933.

Miller, A. D. (2003), The problem with cationic liposome/micelle-based non-viral vector systems for gene therapy, Curr Med Chem, 10, 1195-1211.

Templeton, N. S. (2001), Developments in liposomal gene delivery systems, Expert Opin. Biol. Ther, 1, 1-4.

Uhrikova, D.; Rapp, G.; Kunst, B. H. and Balgavy, P. (1998), Interaction of DNA with DPPC bilayers in the presence of $\mathrm{Mg}$ (II) ions, EMBL DESY Outstation - Hamburg; Project No: ML-98-6.

Received: August 20,2003; Revised: January 27, 2004; Accepted: July 15, 2004. 